Research Article

\title{
Effects of Shrinkage Reducing Agent and Expanded Cement on UHPC Fluidity, Mechanical Properties, and Shrinkage Performance
}

\author{
Tingyu Wang, ${ }^{1}$ Jianqing Gong $\left(\mathbb{D},{ }^{2}\right.$ Bo Chen, ${ }^{1}$ Xiao Gong, ${ }^{1}$ Hongkui Luo, ${ }^{2}$ Yang Zhang, \\ and Zhigang $\mathbf{Q \mathbf { u } ^ { 2 }}$ \\ ${ }^{1}$ Hunan Provincial Expressway Group Limited Company, Changsha, Hunan 410000, China \\ ${ }^{2}$ College of Civil Engineering, Hunan University, Changsha, Hunan 410082, China
}

Correspondence should be addressed to Jianqing Gong; gongjianqing@hnu.edu.cn

Received 16 April 2021; Revised 8 June 2021; Accepted 12 July 2021; Published 22 July 2021

Academic Editor: Youyou Zhang

Copyright (C) 2021 Tingyu Wang et al. This is an open access article distributed under the Creative Commons Attribution License, which permits unrestricted use, distribution, and reproduction in any medium, provided the original work is properly cited.

\begin{abstract}
The purpose of this study was to evaluate the effects of a shrinkage reducing agent (SRA) and Portland expanded cement (PEC) on the fluidity, mechanical properties, and shrinkage performance of ultrahigh-performance concrete (UHPC). The results indicated that the fluidity of the fresh UHPC mortar initially decreased and then increases along as a function of SRA dosage. When the dosage of SRA was $1 \%$, the UHPC mortar fluidity was at its minimum. For dosages exceeding $1 \%$, the additional water-binder ratio of the mortar increased, which in turn increased the UHPC fluidity. That is, the SRA delayed the cement hydration and increased the setting time, which is not conducive for early strength development of UHPC. As the SRA dosage was increased (i.e., $0 \%-2 \%$ ), the autogenous shrinkage of UHPC decreased significantly such that even a small dosage of about $0.5 \%$ SRA was able to effectively reduce drying shrinkage. From the study results, it was also observed that PEC accelerated the loss of fluidity in the fresh UHPC and concurrently promoted the early strength development of UHPC. At 75\% PEC content, the strength enhancement effects tended to be stable. This means that although the addition of PEC will potentially increase the autogenous shrinkage of UHPC, it has the positive effect of inhibiting drying shrinkage provided that the PEC dosage is controlled within the $25 \%-50 \%$ range. Furthermore, morphological analyses using a scanning electron microscope (SEM) indicated that an increase in the SRA dosage loosens the UHPC microstructure, with the formation of the hydration products remaining incomplete, thus ultimately causing the UHPC strength to decrease. Overall, the study findings indicated that $2 \%$ SRA and $25 \%-50 \%$ PEC can effectively reduce the shrinkage of UHPC and are, therefore, recommended as the optimum dosages.
\end{abstract}

\section{Introduction}

Ultrahigh-performance concrete (UHPC) has characteristic features that include ultrahigh mechanical strength, high toughness, and excellent durability, in addition to the ability to adapt to various harsh environments [1-3]. UHPC generally uses a low water-cement ratio and contains various cementitious materials (cement, silica fume, slag, etc.). The autoshrinkage of ordinary concrete was $20 \sim 100 \mu \varepsilon$, and the dry shrinkage was $200 \sim 1000 \mu \varepsilon$; the former is about $1 / 10$ of the latter [4]. Compared to ordinary concrete, Liu et al. [5] reported that the autogenous shrinkage of UHPC at 7 days reached 500 1500 microstrains. Therefore, compared to the typical concrete, the total shrinkage (autogenous shrinkage and drying shrinkage) of UHPC will be higher.

Additionally, due to its unique shrinkage characteristics, it will generally result in more considerable shrinkage from the early setting and hardening during its service life, which will not only cause the matrix to crack [6,7], but also impact the strength and durability severely [8]. The characteristic properties that lead to the suppression of shrinkage and deformation of UHPC are some of the essential factors 
widely used in engineering structures. UHPC is also a hot and challenging research topic.

1.1. Literature Review and Study Motivation. To overcome the disadvantages of UHPC's large shrinkage deformation, several methods have been explored in the literature including changing the curing method [9], adding additives (shrinkage reducing agent [10] and expansion agent [11]), and using Portland expanded cement [12]. Among the additives, the use of shrinkage reducing agent (SRA) is one of the methods currently advocated to reduce autogenous shrinkage and drying shrinkage deformation, and it is considered especially suitable for high-performance concrete [13]. SRA can reduce the surface tension of the capillary pore solution in the UHPC matrix and reduce the negative pressure in the capillary pores, thereby reducing the shrinkage stress caused by the self-drying occurring inside the high-performance concrete [14]. The results of Hatami's study showed that the addition of $2 \%$ SRA could reduce the autogenous shrinkage of concrete by 58\% [15]. Although SRA shows excellent performance in reducing shrinkage, some studies $[16,17]$ have claimed that SRA not only has an adverse effect on coagulation, but also introduces a part of gas that will increase the porosity of the concrete and reduce the compactness of the internal structure, ultimately having an adverse effect on the strength and durability of concrete.

Research studies have been conducted to mitigate the shrinkage of UHPC during the past decades, including the use of supplementary cementitious materials (SCMs) and admixture, and improve the aggregate grading. Park et al. [18] found that the addition of $1 \%$ SRA reduced the $28 \mathrm{~d}$ autogenous shrinkage of UHPC by $8 \%$. Some studies have shown that the incorporation of fly ash into UHPC can increase plastics, reduce water, relieve hydration reaction, and play a filling role, thus reducing the early autoshrinkage of UHPC $[19,20]$. At present, the use of SRA is a straightforward strategy to mitigate the shrinkage of UHPC. In order to achieve a better shrinkage reduction effect, the optimal dosage of the shrinkage reducing agent should be tested and determined. Otherwise, it would exert a negative impact on cement hydration and the strength of UHPC.

Based on the existing literature, some studies have been performed on the mechanical properties, shrinkage, and hydration process of concrete prepared using expanded cement [21-28]. Péra and Ambroise observed good quality strength development in concrete containing expanded cement [24]. Rahman et al. conducted a study on cracking caused by bridge deck shrinkage and discovered that the compressive stress generated by the initial expansion of expanded cement could offset the tensile stresses generated by drying shrinkage [25].

Ramseyer conducted a study on flooring to understand the shrinkage characteristics of shrinkage-compensating cement concrete that could be used for field applications. From their study, Ramseyer found that the expansion and contraction are limited under certain constraint conditions [26]. Although there is an abundance of research literature on the strength, shrinkage, and hydration process of expanded cement concrete (ECC), the research on its combined use with a SRA is limited, hence the motivation for this study $[27,28]$.

1.2. Study Objectives and Scope of Work. Based on the foregoing motivation and to fill the information gap on the combined use of ECC along with SRA, this study sought to develop a mixed proportion of low-shrinkage UHPC mortar. From the reviewed literature, there are very limited research studies on the evaluation of the impact of Portland expanded cement (PEC) and SRA on the performance of UHPC. Previous studies have shown that the addition of SRA and PEC can potentially improve the shrinkage performance of concrete [1-28]. The novelty of this study comes from the fact that after obtaining the optimal dosage of SRA, the SRA and PEC can be compounded to enhance the shrinkage inhibition performance of UHPC to obtain an optimal mix ratio.

In this study, the effects of different SRA contents on the fluidity, mechanical, autogenous shrinkage, and drying shrinkage properties of the UHPC mortar were comparatively evaluated. A scanning electron microscope (SEM) was used to morphologically analyze the microstructure of lowshrinkage UHPC. From this study, it is envisioned that the test results and findings may beneficially contribute to the promotion of wide application of UHPC utilizing a combined mix of PEC and SRA additives in various engineering structures.

\section{Study Plan and Materials Used}

The study plan encompassed the following key tasks: (a) material procurement; (b) mix-design and sample preparation; (c) laboratory testing; (d) data processing and analysis; and (e) synthesis and drawing of conclusions and recommendations. Whilst the rest of the tasks are discussed in the subsequent texts, the materials used, mixing, and sample preparation are discussed in this section. Note in this paper that the words binder and cement have been used interchangeably to refer to cementitious materials.

2.1. Cementitious Materials. The cementitious materials used in this study included cement, silica fume, and fly ash. The cement used was ordinary Portland cement (PO 42.5) produced by the Hunan South Cement Plant of China. The PEC (42.5R) was sourced from the Zhongshan Kebao Cement Plant. The key chemical compositions of these cementitious materials are summarized in Table 1.

2.2. Aggregates and Superplasticizer. The fine aggregate used in the study comprised of 20-40 mesh grade quartz sand without coarse aggregates. The quartz powder comprised of a 325 mesh with a density of $2.645 \mathrm{~g} / \mathrm{cm}^{3}$ and an average particle size of $50.5 \mu \mathrm{m}$. The superplasticizer used was a polycarboxylate superplasticizer with a white powder appearance. It had a solid content of $40 \%$ and a water reducing rate of more than $30 \%$. 
2.3. The Shrinkage Reducing Agent (SRA). The SRA used in the study comprised of a BHY-2A concrete shrinkage reducing agent, which is a pale white turbid liquid. It is compatible with water in any proportion and can also be added to a pumping superplasticizer. It is incredibly convenient to use in construction applications and has a shrinkage rate of $50 \% \sim 80 \%$. The dosage explored in this study ranged from $0.5 \%$ to $2.0 \%$ of the total mass of the cementitious materials.

2.4. Mix-Design Proportions. UHPC with a water-binder ratio of 0.20 was selected as the basic mixing ratio, with the following constituent ratio compositions, namely, $m$ (cement) $: m$ (silica fume) $: m$ (fly ash) $: m$ (quartz sand) $: m$ (quartz powder) $=1: 0.25: 0.10: 1.1: 0.25$. Concrete was calculated based on the apparent density of $2400 \mathrm{~kg} / \mathrm{m}^{3}$. The total amount of cementitious materials was maintained constant. Silica fume, fly ash, and PEC (42.5R) were used to replace the ordinary Portland cement $(\mathrm{PO} 42.5)$ using an internal mixing procedure, with the PEC ratios of $25 \%, 50 \%$, $75 \%$, and $100 \%$, respectively.

The superplasticizer and SRA were added to the mortar matrix using an external mixing method. The dosage of the superplasticizer was $2 \%$ whilst that of the SRA was $0.5 \%, 1 \%$, and $2 \%$, respectively. These dosages were determined and applied as a quantitative ratio of the cementitious materials. The optimal dosage of SRA (1\%) was selected. Then, the negative effect of the shrinkage reducer on UHPC was offset by $\operatorname{EPC}(25 \%, 50 \%, 75 \%$, and $100 \%)$ to obtain the best performance of UHPC. The mix-design proportions along with the corresponding tests are listed in Table 2.

Pour cement, quartz sand, quartz powder, silica fume, fly ash, and water reducing agent into a stirring pot according to the mix ratio in Table 2, and dry mix for 2 min until the raw materials are evenly mixed. Then add the weighed water, stir it slowly for $4 \mathrm{~min}$, and then stir it fast for $4 \mathrm{~min}$ until the material is entirely fluidized. SRA should be added in water before stirring evenly and then mixed with water in the stirring pot. After the fluidity test is completed, the slurry is loaded into a steel die of $40 \mathrm{~mm} \times 40 \mathrm{~mm} \times 160 \mathrm{~mm}$, covered with a plastic film, and demolded after natural curing for $24 \mathrm{~h}$.

From Table 2, it is evident that the quantitative ratios of water, quartz sand, quartz power, silica fume, fly ash, and superplasticizer were maintained constant at 216.2, 880.9, $200.2,200.2,80.1$, and $21.6 \mathrm{~kg} / \mathrm{m}^{3}$, respectively, throughout the mix-design process. In fact, quartz powder and silica fumes had the same ratio proportion of $200.2 \mathrm{~kg} / \mathrm{m}^{3}$. On the other hand, the ratio proportions of $\mathrm{H}_{2} \mathrm{O}$, ordinary Portland cement (PO 42.5), SRA, and PEC (42.5 R), as seen in the table, were varied. At minimum, three sample replicates were prepared per material component per mix-design proportion.

\section{Laboratory Experimentation}

As discussed below, the laboratory tests conducted in this study included fluidity assessment mechanical properties (namely, compressive and tensile strengths) and shrinkage evaluation covering both autogenous and drying shrinkage. Morphological evaluation to characterize the UHPC microstructure was accomplished using the SEM and is also discussed in this section.

3.1. Fluidity Assessment. According to GBT2419-2005 "Test method for fluidity of cement mortar" [29], the fluidity is typically conducted using a truncated cone round mold with an upper mouth inner diameter of $70 \mathrm{~mm} \pm 0.5 \mathrm{~mm}$, a lower mouth inner diameter of $100 \mathrm{~mm} \pm 0.5 \mathrm{~mm}$, and a height of $60 \mathrm{~mm} \pm 0.5 \mathrm{~mm}$. The testing device used in this experimentation was the NLD-35 cement mortar fluidity tester. The specific operational steps were as follows: quickly put the mixed cement mortar into the truncated cone mold based on the specification, gently lift the truncated cone round mold vertically upwards, and then, immediately press the start button on the counter to start the jumping table to complete a cycle of 25 beats. After the jumping table jumps, use a caliper with a range of $300 \mathrm{~mm}$ to measure the extension diameter of the mortar bottom in two directions perpendicular to each other and calculate the average value. The integer of the average value is the fluidity of the cement mortar. Three replicate tests were performed per mix-design proportion.

3.2. Compressive and Flexural Strength Testing. The compressive and flexural strengths were determined based on the GB/T17671-1999 "Method of testing cements-Determination of strength (IOS)" [30]. The size of the specimen is $40 \mathrm{~mm} \times 40 \mathrm{~mm} \times 160 \mathrm{~mm}$. After 24 hours, the mold is removed and cured for 3,7 , and 28 days, respectively, under standard curing conditions (i.e., temperature $20 \pm 2^{\circ} \mathrm{C}$ and humidity $>95 \%)$. Three sample replicates were tested per mix-design proportion per test type/condition.

3.3. Autogenous Shrinkage Evaluation. The autogenous shrinkage value was measured based on the test method proposed by Jensen and Hansen [31], which is a combination of unique bellows and a noncontact probe. The mixed UHPC mortar (or paste) was placed into the unique bellows with inner and outer diameters of $20 \mathrm{~mm}$ and $30 \mathrm{~mm}$, respectively, and a length of $340 \pm 5 \mathrm{~mm}$. Plugs were used to seal the ends of the pipes, with one end of the bellows being fixed on the steel supports, while the other end is kept freely moving on the bracket. The position of the displacement sensors was then adjusted to monitor the displacement change of the free end of the specimen in real time. For each mix-design proportion, a minimum of three sample replicates were tested.

3.4. Drying Shrinkage Evaluation. The drying shrinkage value was determined according to JGJ/T70-2009 "Standard for test method of performance on building mortar" [32]. The size of the specimen was $40 \mathrm{~mm} \times 40 \mathrm{~mm} \times 160 \mathrm{~mm}$, with the probes embedded at both ends of the specimen. The specimen with mold was cured in a standard curing box for 7 days and thereafter removed from the mold. The initial length of the specimen was tested and then placed into the 
dry shrinkage curing box (temperature $20 \pm 2^{\circ} \mathrm{C}$ and relative humidity $(60 \pm 5) \%)$ for $7 \mathrm{~d}, 14 \mathrm{~d}, 21 \mathrm{~d}, 28 \mathrm{~d}$, and $56 \mathrm{~d}$. Three sample replicates were used for dry shrinkage evaluation per mix-design proportion.

3.5. SEM Microstructure Characterization. For the SEM test, the samples were broken into $1 \mathrm{~cm}^{3}$ small pieces after curing to the specified age and then immediately put into absolute ethanol to stop hydration for 7 days. Thereafter, they were put in a vacuum drying oven at $60 \pm 5^{\circ} \mathrm{C}$ to dry to a constant weight. Gold was sprayed onto the surface of the vacuumdried sample for it to be conductive. A scanning electron microscope was then used for morphological testing and characterizing the microstructure of the UHPC matrix, utilizing three sample replicates per mix-design proportion.

\section{Test Results, Analysis, and Synthesis}

The laboratory test results are presented, analyzed, and synthesized in this section. These test results include the effects of SRA and PEC additives on UHPC fluidity, mechanical properties, and shrinkage characteristics. The SEM morphological results in terms of the UHPC microstructure as a function of SRA dosages are also presented and analyzed in this section.

4.1. Effects of SRA and PEC on UHPC Fluidity. Discussed below are the effects of the SRA and PEC additives on the fluidity of the UHPC paste (matrix). The additive impact, which was quantified in terms of the fluidity loss, was assessed in comparison to the control UHPC without any SRA or PEC additive.

4.1.1. SRA Effects on UHPC Fluidity Loss. Figure 1 shows the influence of different SRA dosages (i.e., $0 \%, 0.5 \%, 1.0 \%$, and $2.0 \%$, respectively) on the fluidity of UHPC. The results in Figure 1(a) show that the fluidity of UHPC paste decreases with an increase in the SRA dosage at $0 \mathrm{~min}$ and $30 \mathrm{~min}$ for smaller dosages less than $1.0 \%$. When the dosage exceeds $1.0 \%$, the fluidity of the UHPC paste at $0 \mathrm{~min}$ and $30 \mathrm{~min}$ increases with the SRA dosage. Thus, the overall results exhibit an initial declining trend followed by an increase when the SRA dosage is over $1.0 \%$.

When the dosage is $1.0 \%$, the fluidity in Figure 1(a) is at minimum, which are $249 \mathrm{~mm}$ and $237 \mathrm{~mm}$, respectively, for $0 \mathrm{~min}$ and $30 \mathrm{~min}$, respectively. This response behavior may be caused by the following two reasons: (a) some chemical components in the SRA have a certain inhibitory effect on the performance of the superplasticizer, and/or (b) the SRA used in this experiment was liquid and contained water that caused the water-to-binder ratio of the UHPC paste to increase. This may have led the fluidity to gradually increase when the SRA dosage exceeded 1.0\%. Therefore, the fluidity of the UHPC paste exhibits an initial declining trend that is followed by an increase in SRA dosage exceeding 1.0\%.

Figure 1(b) shows the influence of different SRA dosages $(0.0 \%, 0.5 \%, 1.0 \%$, and $2.0 \%)$ on the UHPC fluidity loss.
When comparing with the control UHPC at 0.0\% SRA, it was observed from the results in Figure 1(b) that the incorporation of SRA would result in a significant reduction in the fluidity loss of the UHPC paste. When the SRA dosage was increased from $0.5 \%$ to $2.0 \%$, the fluidity loss hardly changed, indicating a lack of harmful effects on the fluidity of the UHPC paste with the variation in the SRA dosage. This phenomenon was caused by the SRA additive greatly reducing the evaporation rate of the pore solution in the concrete, whilst at the same time, also having a certain degree of inhibition on the hydration of the cement $[33,34]$. This ultimately caused the fluidity loss of the UHPC paste to be relatively small as the SRA dosage was varied.

4.1.2. PEC Effects on UHPC Fluidity. Figure 2 shows the influence of different PEC dosages ( $0 \%, 25 \%, 50 \%, 75 \%$, and $100 \%$, respectively) on the UHPC fluidity. The results in Figure 2(a) show that the fluidity of the UHPC paste at $0 \mathrm{~min}$ and $30 \mathrm{~min}$ decreases as the replacement amount of PEC over ordinary Portland cement was increased. The fluidity is the lowest, with minimum values of $219 \mathrm{~mm}(0 \mathrm{~min})$ and $190 \mathrm{~mm}$ (30 min), respectively, at 100\% PEC.

Figure 2(b) shows the influence of PEC dosage (0\%, 25\%, $50 \%, 75 \%$, and $100 \%$, respectively) on the UHPC fluidity loss. When compared to the control UHPC without PEC (i.e., $0.0 \%$ ), it is apparent from the figure that the fluidity loss of the UHPC paste was significantly accelerated after the ordinary Portland cement was replaced with the same amount of PEC but declined slightly for 100\% PEC dosage. Therefore, when the PEC dosage is greater than $75 \%$, the fluidity loss will decrease and not increase any further through to $100 \%$ PEC dosage.

In comparison with the ordinary Portland cement, the clinker of PEC contains more active slag components. This produces a pozzolanic effect in the initial stages of cement hydration, promotes the hydration process, releases the heat of hydration, accelerates the evaporation of water, and consumes a great amount of water in the reaction process [35]. This in turn significantly reduces the fluidity of the paste and, in fact, accelerates the fluidity loss. As the dosage of PEC increases (i.e., from $0.0 \%$ to $75 \%$ ), the expansion components contained within the paste will also participate in the reaction and partially consume some water, causing the fluidity loss of the UHPC paste within 30 minutes to increase. Nevertheless, when the dosage of PEC exceeds 75\%, the contained active ingredients may reach the peak value for promoting cement hydration. Under this condition, the reaction rate is not improved by increasing the $\mathrm{PEC}$ dosage and causes the 30 min UHPC fluidity loss to have no change with any further increase in the PEC dosage.

\subsection{Effects of SRA and PEC on UHPC Mechanical Properties.} As previously mentioned, the effects of the SRA and PEC additives on the mechanical properties of the UHPC paste (matrix) were measured and quantified in terms of the compressive and tensile strengths, respectively. The test results of these laboratory evaluations are analyzed and discussed below. 
TABLE 1: The main chemical components of cement, silica fume, and fly ash (\%).

\begin{tabular}{lcccccccccc}
\hline Component & $\mathrm{SiO}_{2}$ & $\mathrm{Al}_{2} \mathrm{O}_{3}$ & $\mathrm{Fe}_{2} \mathrm{O}_{3}$ & $\mathrm{CaO}$ & $\mathrm{MgO}$ & $\mathrm{SO}_{3}$ & $\mathrm{~K}_{2} \mathrm{O}$ & $\mathrm{Na}_{2} \mathrm{O}$ & $\mathrm{C}$ & $\mathrm{Loss}$ \\
\hline PO 42.5 & 21.10 & 5.50 & 2.70 & 65.40 & 3.40 & 1.90 & - & - & - \\
$42.5 \mathrm{R}$ & 31.62 & 7.48 & 12.58 & 29.19 & 32.11 & 0.43 & 0.31 & 0.3 & - \\
Silica fume & 95.2 & - & 0.59 & 1.85 & 0.27 & - & 0.86 & 0.17 & 1.06 \\
Fly ash & 52.52 & 32.62 & 8.29 & 4.63 & 0.73 & 1.21 & - & - & - & 3.87 \\
\hline
\end{tabular}

TABLE 2: The mix-design proportions $\left(\mathrm{kg} / \mathrm{m}^{3}\right)$.

\begin{tabular}{|c|c|c|c|c|c|c|c|c|c|}
\hline Test & $\begin{array}{l}\text { Water } \\
\left(\mathrm{H}_{2} \mathrm{O}\right)\end{array}$ & $\begin{array}{c}\text { PO } 42.5 \\
\text { cement }\end{array}$ & $\begin{array}{l}\text { Quartz } \\
\text { sand }\end{array}$ & $\begin{array}{l}\text { Quartz } \\
\text { powder }\end{array}$ & Silica fume & Fly ash & Superplasticizer & $\begin{array}{c}\text { Shrinkage } \\
\text { reducing agent }\end{array}$ & PEC $42.5 \mathrm{R}$ cement \\
\hline S0/E0 & 216.2 & 800.8 & 880.9 & 200.2 & 200.2 & 80.1 & 21.6 & 0 & 0.0 \\
\hline S0.5 & 216.2 & 800.8 & 880.9 & 200.2 & 200.2 & 80.1 & 21.6 & 5.4 & 0.0 \\
\hline S1 & 216.2 & 800.8 & 880.9 & 200.2 & 200.2 & 80.1 & 21.6 & 10.8 & 0.0 \\
\hline S2 & 216.2 & 800.8 & 880.9 & 200.2 & 200.2 & 80.1 & 21.6 & 21.4 & 0.0 \\
\hline E25 & 216.2 & 600.6 & 880.9 & 200.2 & 200.2 & 80.1 & 21.6 & 10.8 & 200.2 \\
\hline E50 & 216.2 & 400.4 & 880.9 & 200.2 & 200.2 & 80.1 & 21.6 & 10.8 & 400.4 \\
\hline E75 & 216.2 & 200.2 & 880.9 & 200.2 & 200.2 & 80.1 & 21.6 & 10.8 & 600.6 \\
\hline E100 & 216.2 & 0 & 880.9 & 200.2 & 200.2 & 80.1 & 21.6 & 10.8 & 800.8 \\
\hline
\end{tabular}

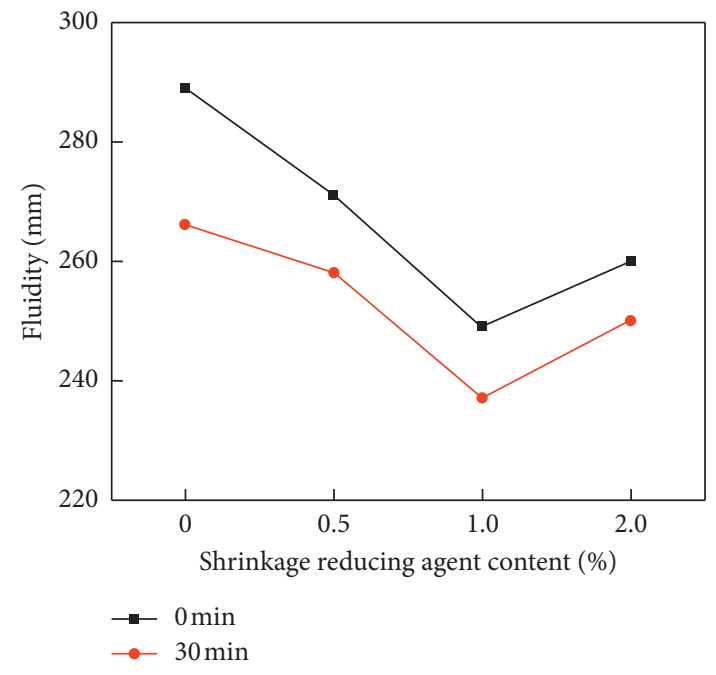

(a)

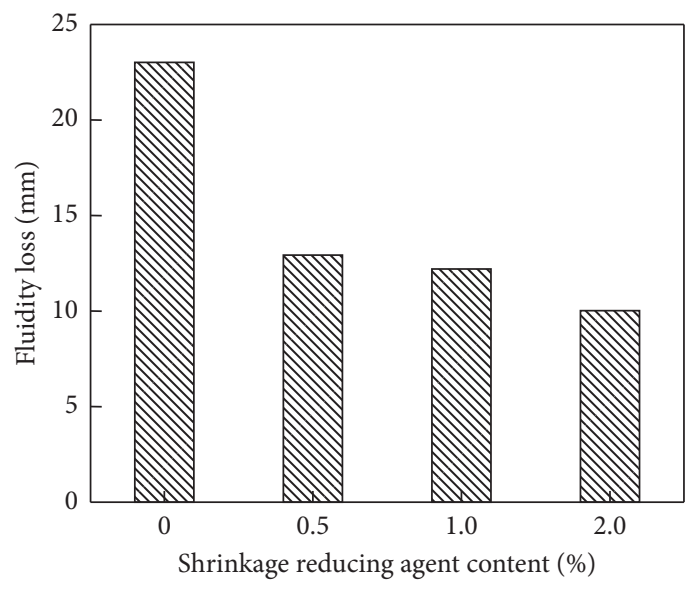

(b)

FIGURE 1: Effects of SRA content on the UHPC fluidity response behavior. (a) Fluidity value (0 min and 30 min). (b) Fluidity loss.

4.2.1. SRA Effects on the UHPC Compressive and Tensile Strengths. Figure 3 shows the influence of SRA dosages, namely, $0.0 \%, 0.5 \%, 1.0 \%$, and $2.0 \%$, respectively, on the compressive and flexural strength of UHPC as a function of curing time. It is evident from the figure that SRA has adverse effects on the compressive and flexural strengths of UHPC. The detrimental effect on the strength of the UHPC is more apparent with an increase in the SRA dosage. As shown in Figure 3(a), the 3-day (d) compressive strength decreased by $20.8 \%, 31.2 \%$, and $41.0 \%$, respectively, while the 28 -day compressive strength decreased by $18.9 \%, 28.6 \%$, and $37.1 \%$, respectively, as the SRA dosage was increased from $0.0 \%$ to $2.0 \%$. When comparing age (i.e., $3 \mathrm{~d}$ to $28 \mathrm{~d}$ curing period), it is also evident from the figure that the SRA additive had less influence on the early strength evolution-that is, the $3 \mathrm{~d}$ strength is the lowest whilst the highest occurred at $28 \mathrm{~d}$ [36].

Figure 3(b) shows that the evolution of the flexural strength is the same as that of the compressive strength. That is, the flexural strength decayed with an increase in the SRA dosage but exhibited an increasing trend as a function of age (i.e., curing period) for all the SRA dosages evaluated. The highest registered flexural strength occurred after $28 \mathrm{~d}$ of curing at $0.0 \%$ SRA, which detrimentally decreased by $17.1 \%, 33.2 \%$, and $43.8 \%$, respectively, as the SRA dosage was increased.

In general, Figure 3 indicated that SRA has detrimental effects on the mechanical properties of UHPC. This decay in 


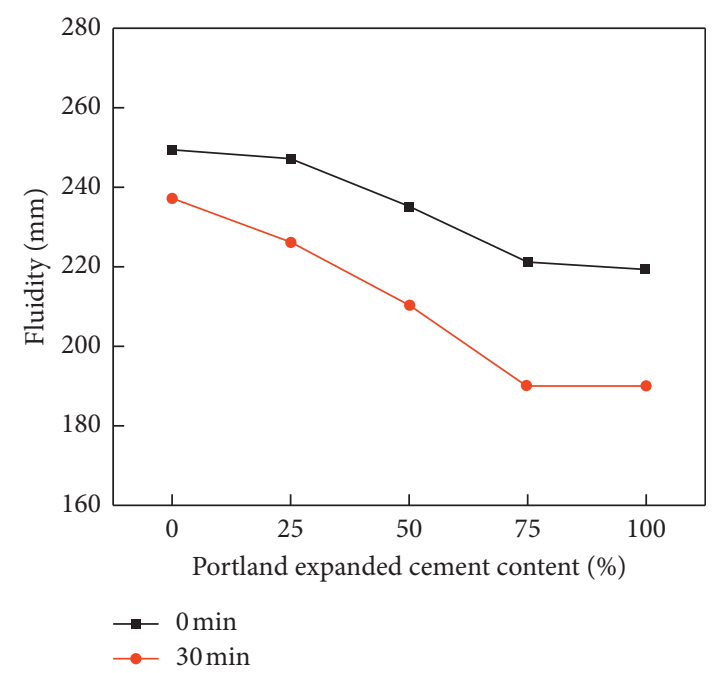

(a)

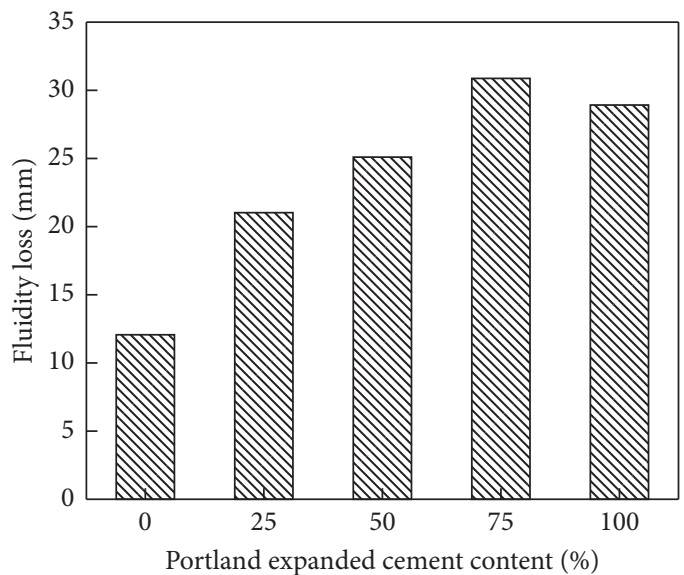

(b)

FIgURe 2: Effects of PEC content on the UHPC fluidity response behavior. (a) Fluidity value (0 min and 30 min). (b) Fluidity loss.

the UHPC strength was attributed to three reasons as follows. First, the incorporation of SRA tends to extend the concrete setting time by about $25 \%$ [37], and thus, an increase in the SRA dosage will significantly improve this delay effect. Second, SRA will affect the progression of cement hydration, which will adversely hinder the increase in cement paste pore solution alkalinity, delay the generation of the hydration product $\mathrm{Ca}(\mathrm{OH})_{2}$, reduce the hydration heat of cement hydration, delay the peak heat release [38], and reduce the generation of hydration products in the early stages of concrete hydration-which ultimately affects the early strength development of concrete. Third, the incorporation of SRA has an air-entraining effect to a certain extent [39]. At the same time, the fluidity of concrete increases-a phenomenon that effectively changes the pore structure and affects the strength of the concrete.

Overall, the incorporation of SRA has been demonstrated to be harmful to the strength development of UHPC, with the strength decay being more pronounced as the SRA dosage increases. On this basis and if shrinkage is not an issue of concern, SRA may not be the benefit additive for UHPC strength enhancement.

4.2.2. PEC Effects on the UHPC Compressive and Flexural Strengths. Figure 4 shows the effects of different PEC dosages (i.e., $0 \%, 25 \%, 50 \%, 75 \%$, and $100 \%$, respectively) on the compressive and flexural strength of UHPC as a function of curing time. The compressive strength of UHPC at different ages shows an increasing trend with an increase in the PEC dosage. When the dosage exceeded $50 \%$, the evolution rate of the UHPC compressive strength at $3 \mathrm{~d}$ and $7 \mathrm{~d}$ aging started to gradually slow down. For PEC dosage over $75 \%$, the $28 \mathrm{~d}$ compressive strength declined slightly, but still remained at over $90 \mathrm{MPa}$. From the figure, the peak compressive strength occurred for $75 \%$ PEC at $28 \mathrm{~d}$ age curing, with a value of $116.9 \mathrm{MPa}$.
In general, the flexural strength of the hardened UHPC paste had the same growth trend as that of the compressive strength. As evident in Figure 4(b), the flexural strength increased alongside an increase in the PEC dosage. However, the PEC dosage effect on the early flexural strength $(3 \mathrm{~d}$ and $7 \mathrm{~d}$ ) evolution was not as pronounced as that of the $28 \mathrm{~d}$ curing period. At the age of $28 \mathrm{~d}$, the flexural strength rose rapidly with an increase in the PEC dosage. From the figure, it can be observed that the UHPC flexural strength reached its maximum value of $32.5 \mathrm{MPa}$ for a PEC dosage of $100 \%$.

As previously mentioned in Section 4.1.2, PEC has active slag components and was used to replace ordinary Portland cement in UHPC. It can thus potentially play the role of microfilling and compacting the pore structure of the hardened UHPC paste [35]. However, slag has an intense pozzolanic activity, which not only promotes the hydration process of cement to a certain extent, but it also offsets the delaying effect of SRA on the cement hydration process, accelerates the formation of hydration products, and develops the strength of the hardened UHPC paste. This enhancement effect did not change with an increase in the PEC dosage. When the PEC dosage is $75 \%$, the hydration of the cement matrix becomes saturated and the chemical reactions stabilize.

Overall, whilst the strength of the hardened UHPC paste increased significantly over the control UHPC without any PEC additives (i.e., 0\%), the UHPC strength did not increase significantly with the variation of the PEC dosage. That is, when the PEC dosage was progressively increased from $25 \%$ to $100 \%$, the strength gain was marginal.

4.3. Effects of SRA and PEC on the Autogenous Shrinkage of UHPC. The test results of the effects of the SRA and PEC additives on the autogenous shrinkage of the UHPC paste (matrix) are presented and discussed in this section. In this study, the shrinkage characteristics of UHPC were 


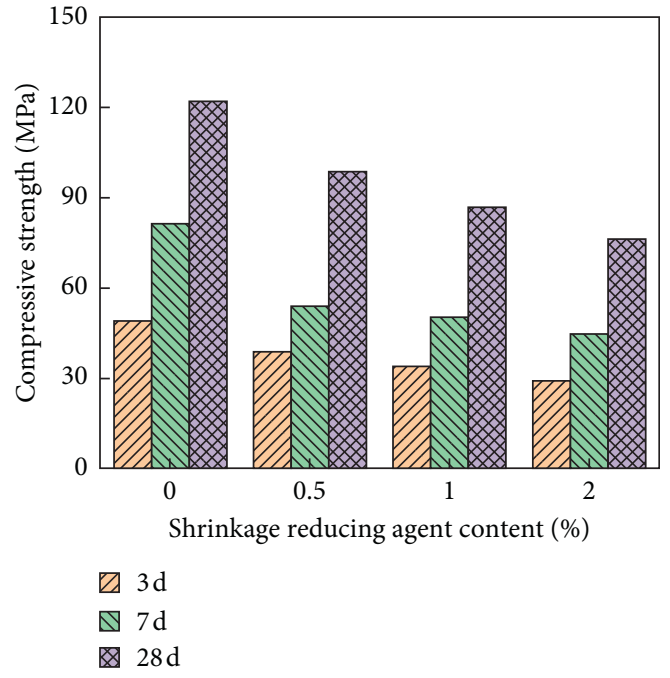

(a)

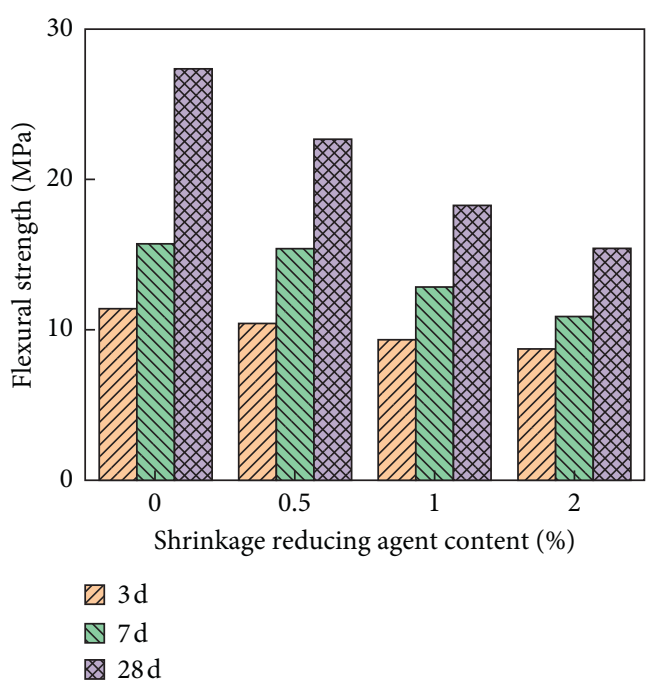

(b)

FIGURE 3: Effects of SRA on the UHPC mechanical properties (d=days). (a) Compressive strength. (b) Flexural strength.

comparatively measured and quantified as a function of the additives (namely, SRA and PEC) and age (in hours).

4.3.1. SRA Effects on the Autogenous Shrinkage of UHPC. Figure 5 shows the effects of SRA on the autogenous shrinkage of UHPC. The SRA dosages evaluated in this study were $0 \%(\mathrm{~S} 0 / \mathrm{E} 0), 0.5 \%(\mathrm{~S} 0.5), 1.0 \%(\mathrm{~S} 1)$, and $2.0 \%(\mathrm{~S} 2)$, respectively. The results in Figure 5 show that in comparison with the control group (namely, S0/E0), the incorporation of SRA significantly reduced the autogenous shrinkage of UHPC. From the figure, the inhibitory effects of SRA incorporation on UHPC's autogenous shrinkage are more apparent as the dosage was increased. That is, the least shrinkage values were recorded for $2.0 \%$ SRA, whilst the control (i.e., 0\% SRA) had the highest shrinkage values at all aging levels. However, of interest was that the shrinkage value associated with S0.5 (0.5\% SRA) was lower than that of S1 (1.0\% SRA). This was not quite the same as previous studies [18].

In general, Figure 5 demonstrates that SRA has a positive effect on the shrinkage resistance of UHPC. This enhancement effect is attributed to the following three reasons. First, SRA has the potential to reduce the surface tension of the cement paste capillary solution, which results in additional stress of capillary due to water loss in the cement hydration process being reduced. This inherently reduces the shrinkage stress of capillary due to the water loss in the cement hydration process-ultimately leading to a decrease in the overall autogenous shrinkage of UHPC [33]. Second, SRA has a microexpansion effect on the cement paste in the early stages of curing that can partially serve as compensation for some shrinkage during the hydration process of the cement, thereby reducing the autoshrinkage effect [40]. Third, in the cement paste system containing SRA, the reactants $\mathrm{Ca}(\mathrm{OH})_{2}$ and ettringite have high supersaturation at the initial stages of hydration [41]. At the same time, the presence of SRA will delay the process of cement hydration. Furthermore, the sulfur-containing crystal products generated in the later stages of hydration may generate microswelling effects that will lead to decay in UHPC shrinkage under the action of SRA [42].

4.3.2. PEC Effects on the Autogenous Shrinkage of UHPC. The laboratory experimentation for PEC evaluation in this study was based on the mix-design proportions of $2.0 \%$ superplasticizer and $1.0 \%$ SRA whilst the PEC (42.5R) content was varied from $25 \%$ to $100 \%$ (i.e., $25 \%, 50 \%, 75 \%$, and $100 \%$, respectively) as a replacement for ordinary Portland cement (PO 42.5). Figure 6 shows the effects of different PEC dosages on the autogenous shrinkage of UHPC, namely, S0/E0 (0\%), E25 (25\%), E50 (50\%), E75 (75\%), and E100 (100\%), respectively. The results show that the autogenous shrinkage of UHPC generally increased with an increase in the PEC content for all the aging conditions from zero through to 84 hours (h). Compared to the control group (i.e., S0/E0), the $72 \mathrm{~h}$ autogenous shrinkage increased by $10.7 \%, 24.1 \%, 25.6 \%$, and $28.9 \%$ for $25 \%, 50 \%, 75 \%$, and $100 \%$ PEC, respectively.

Figure 6 shows that the first peak autogenous shrinkage of the control group (S0/E0) appeared at about $20 \mathrm{~h}$. When the PEC dosage was $25 \%$, the autogenous shrinkage peaks occurred at about $30 \mathrm{~h}$, respectively. As evident from the figure, the early life of the UHPC generally exhibited pronounced shrinkage with stability (curve flattening) occurring after $12 \mathrm{~h}$, except for $100 \%$ PEC that seems to stabilize after about $36 \mathrm{~h}$. When compared to the 25\% PEC enhanced group, the autogenous shrinkage of S0/E0 appears to develop at a slower rate, which is conducive for the development of concrete performance. For PEC contents exceeding 50\%, the autogenous shrinkage peak appeared at about $12 \mathrm{~h}$ and tended to stabilize thereafter, with the curves almost flattening out. 


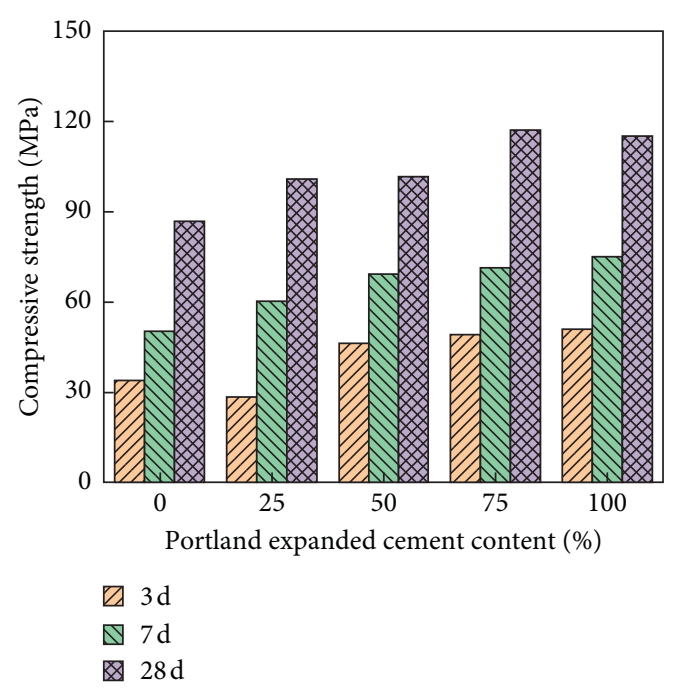

(a)

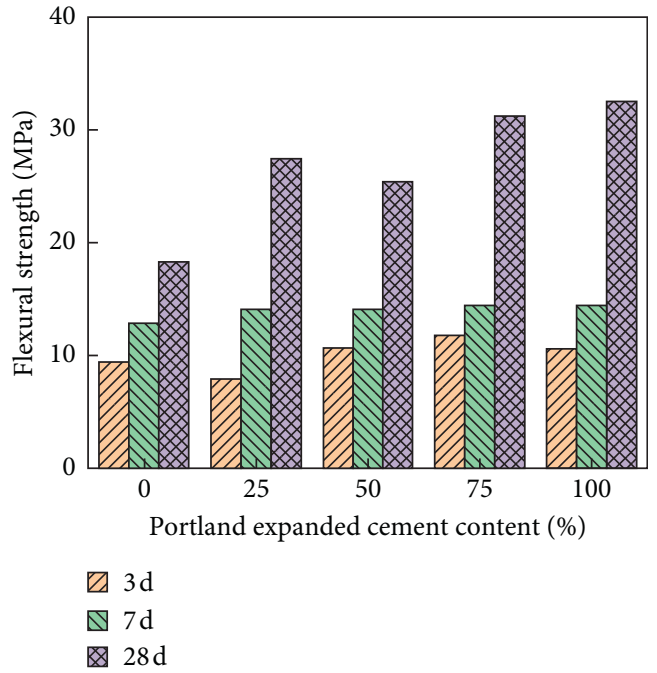

(b)

FIgURE 4: Effects of PEC on the UHPC mechanical properties ( $d=$ day). (a) Compressive strength. (b) Flexural strength.

The literature indicates that the slag powder provides intense and rapid pozzolanic effects because PEC has active slag components in it [43]. When incorporated into UHPC, the cement hydration reaction will be accelerated, and the microstructure of the hydration products will be compacted. As a result, the autogenous shrinkage of UHPC increases as the PEC dosage is increased. However, with a small PEC dosage (i.e., 25\%), the expansion source contained in PEC can have enough water to participate in the cement hydration process and produce more hydration products. This inherently compensates for shrinkage and allows the measured autogenous shrinkage value to decline. However, the autogenous shrinkage in the later stages will increase further with the additional hydration time. Thus, at 25\% PEC, the autogenous shrinkage in the later stage was still higher than that of the control group (S0/E0) by about $10.7 \%$.

4.4. Effects of SRA and PEC on the Drying Shrinkage of UHPC. Like autogenous shrinkage, the effects of SRA and PEC additives on UHPC were comparatively measured and quantified as a function of age (in hours). The test results and analyses of this laboratory experimentation are discussed in this section.

4.4.1. SRA Effects on UHPC Drying Shrinkage. Researchers have widely used SRA as one of the concrete shrinkage reduction measures since its development $[44,45]$. Adding a shrinkage reducing agent into the cement mortar system can effectively reduce the drying shrinkage of the UHPC paste. Figure 7 shows the effects of different SRA dosages, namely, $0 \%$ (S0/E0), 0.5\% (S0.5), 1.0\% (S1), and $2.0 \%$ (S2), respectively, on the drying shrinkage of UHPC as a function of curing period. The figure shows that when the SRA dosage is $0.5 \%$, the drying shrinkage value at $56 \mathrm{~d}$ was $28.6 \%$ lower than that of the control group, i.e., S0/E0 with $0 \%$ SRA. For $1.0 \%$ SRA dosage, the $28 \mathrm{~d}$ drying shrinkage value was similar to that of the control group with overlapping points. However, its drying shrinkage value of $56 \mathrm{~d}$ was lower than that of the control group. Similarly, the $2 \%$ SRA drying shrinkage values for $14 \mathrm{~d}, 21 \mathrm{~d}$, and $28 \mathrm{~d}$ were lower than that of the control group by $3.7 \%, 12.4 \%$, and $36.1 \%$, respectively.

For cement-based materials, the effects of inhibiting shrinkage have been proven in the literature $[14-16,44]$ to increase with an increase in the SRA dosage. This study has yielded different results, namely, a low dosage of SRA can effectively reduce the drying shrinkage of UHPC at the later aging stage. By contrast, an increase in the SRA dosage will instead undesirably increase the drying shrinkage of UHPC.

As previously mentioned, a shrinkage reducing agent will reduce the surface tension of the pore solution. According to the Young-Laplace formulation [46], the negative capillary pressure will decrease as the surface tension of the pore solution decreases in order to reduce the shrinkage stress caused by self-drying inside the concrete, which reduces the drying shrinkage. Therefore, an appropriate SRA dosage can effectively inhibit the drying shrinkage of the UHPC paste.

Furthermore, SRA will reduce the rate of cement hydration, thereby delaying the hydration process. In a nonstandard curing environment in the middle and later stages, the lack of sufficient water to participate in the cement hydration process leads to incomplete hydration and insufficient hydration products to fill the pore structures in time [33-35]. This reduces the internal density of the concrete due to the formation of many harmful pores and is not conducive for the concrete itself to resist the shrinkage stress. This detrimental effect is more apparent with an increase in the SRA dosage. When the SRA dosage is high, the enhancement effects of SRA on the drying shrinkage are significantly more potent than the inhibition effect and ultimately lead to more considerable drying shrinkage. The hydration of cement develops slowly with age, and the 


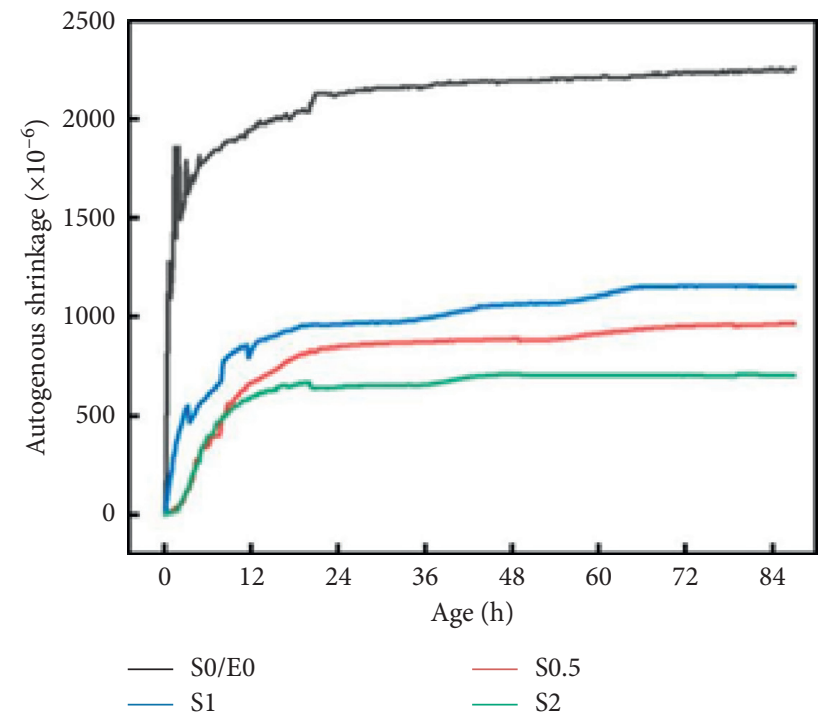

FIGURE 5: Effects of SRA on the autogenous shrinkage of UHPC ( $h=$ hours).

formed sulfur-containing crystal products will fill parts of the voids. Under these conditions, there is no free water loss inside the concrete to cause self-drying shrinkage. With the free development of the hydration products, a certain expansion effect will be produced to compensate for some shrinkage. The macroscopic manifestation of this phenomenon is a decrease in the later drying shrinkage.

Overall, the results in Figure 7 show that the shrinkage reduction effect is the best (i.e., lowest values) when the SRA dosage is $0.5 \%$ and would be deemed as the optimum dosage for minimizing drying shrinkage. Between $12 \mathrm{~h}$ and $50 \mathrm{~h}$ curing period, $2.0 \%$ SRA exhibits the poorest reduction effect with the highest shrinkage values.

4.4.2. PEC Effects on UHPC Drying Shrinkage. Figure 8 shows the influence of different PEC dosages (0 100\%) on the drying shrinkage of UHPC as a function of curing period. The results in the figure generally indicate that after using PEC (42.5R) to replace the ordinary Portland cement (PO 42.5), the drying shrinkage of the hardened UHPC paste decreased progressively as a function of curing period. As the PEC dosage increased, the shrinkage reduction effect became more apparent. In comparison with the control group (i.e., S0/E0), Figure 8 shows that the drying shrinkage values of $56 \mathrm{~d}$ cured UHPC decreased by about $11.6 \%, 26.4 \%$, $27.6 \%$, and $33.3 \%$, respectively.

From Figure 8, it can be concluded that PEC has a positive effect on enhancing the drying shrinkage resistance of UHPC. This enhancement effect is attributed to the following three reasons $[47,48]$. First, the active slag in PEC has a pozzolanic effect that promotes the cement hydration process, accelerates the formation of hydration products, and improves the pore structure, which ultimately increases the density of the hardened paste and has a positive effect on inhibiting drying shrinkage. Second, there are expansion sources in PEC that can potentially produce certain expansion effects in the cement paste, and with the development of the hydration reaction process, it will offset some of the drying shrinkage. Third and lastly, as the UHPC ages as a function of time, the internal structure of UHPC becomes denser, the drying shrinkage rate slows down, and the hydration products continue to increase, which possibly leads to a reduction in later shrinkage.

Overall, the inhibition effects on the drying shrinkage of UHPC were best at 100\% PEC, with the lowest measured drying shrinkage values. Interpretively, this means that completely replacing the ordinary Portland cement (PO 42.5) with $100 \%$ PEC will yield the best shrinkage resistance enhancement in UHPC and can thus be inferred as the optimum dosage. As theoretically expected, $0.0 \%$ PEC (i.e., S0/E0) was the poorest performer with the highest drying shrinkage values seconded by $25 \%$ PEC, i.e., E25. That is, the higher the PEC dosage, the better the enhancement effects in arresting the drying shrinkage in UHPC.

4.5. SEM Microstructure Results. In this study, the effect of shrinkage reducer on the performance of UHPC was first studied to obtain the best amount of shrinkage reducer. However, shrinkage reducer would lead to the decline of the performance of UHPC. Therefore, the phenomenon of its occurrence was explained by scanning electron microscopy. Expanded cement used in engineering is used to compensate for the adverse effect of shrinkage reducer on UHPC and obtain better performance. Therefore, SEM experimental analysis of SRA is needed in this experiment.

Figure 9 illustrates the SEM images of UHPC with different SRA dosages, namely, $0.5 \%, 1.0 \%$, and $2.0 \%$, respectively, at $28 \mathrm{~d}$ aging. It can be seen from Figures 9(a), $9(\mathrm{~d})$, and $9(\mathrm{~g})$ that the microstructure of the hardened UHPC paste became loose and porous with an increase in the SRA dosage, resulting in harmful voids that cause the compactness of the hardened UHPC paste to decrease $[49,50]$. In Figure $8(\mathrm{~h})$, the microstructure of the UHPC paste mixed with $2 \%$ SRA shows more pores than the SEM 


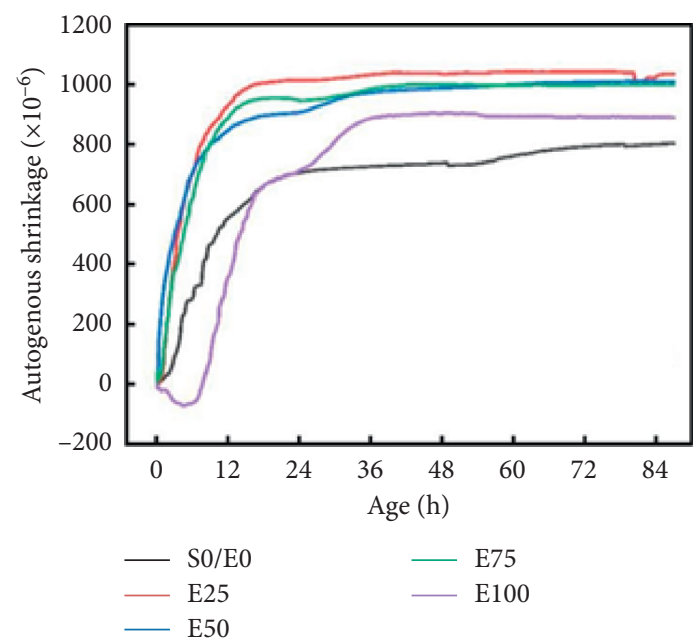

FIGURE 6: Effects of PEC on the autogenous shrinkage of UHPC ( $h=$ hours).

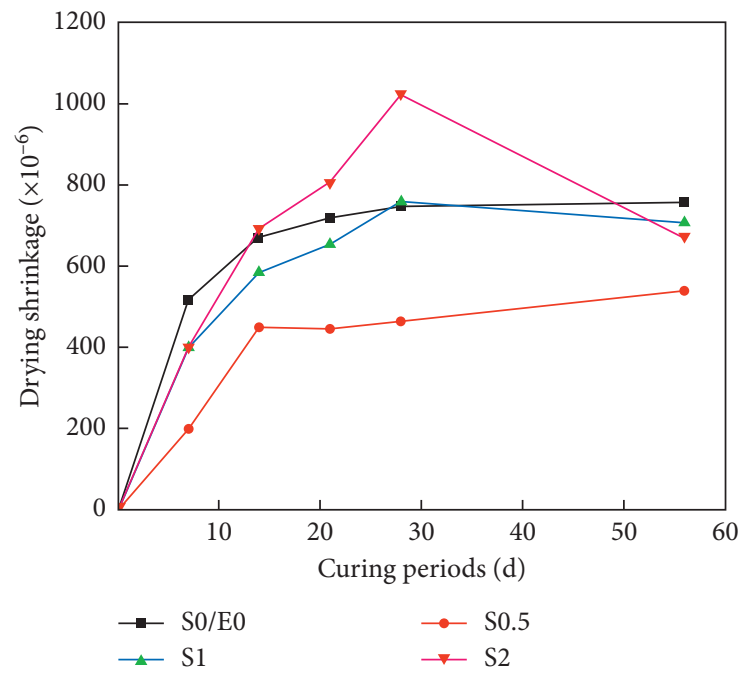

FiguRE 7: Effects of SRA on the drying shrinkage of UHPC ( $d=$ days).

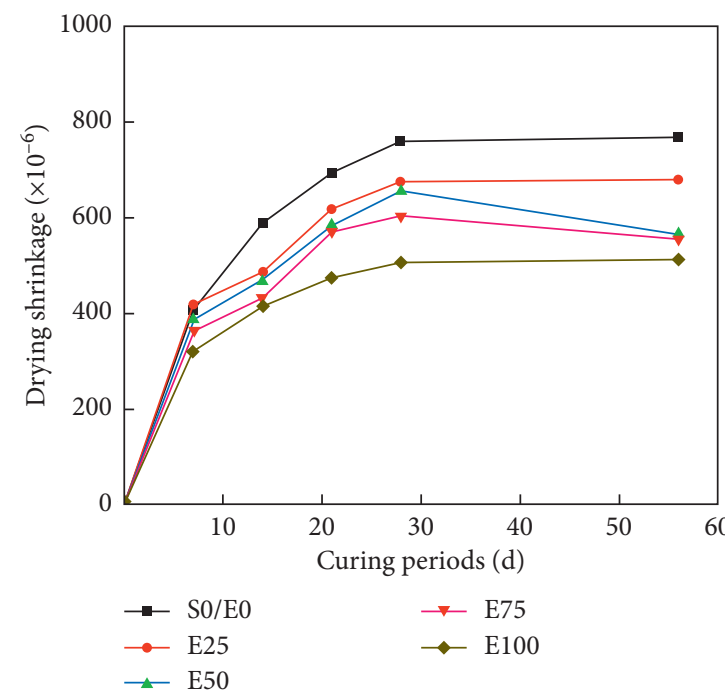

Figure 8: Effects of PEC on the drying shrinkage of UHPC ( $d=$ days). 


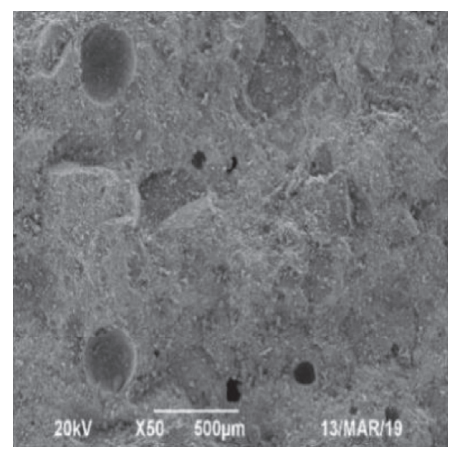

(a)

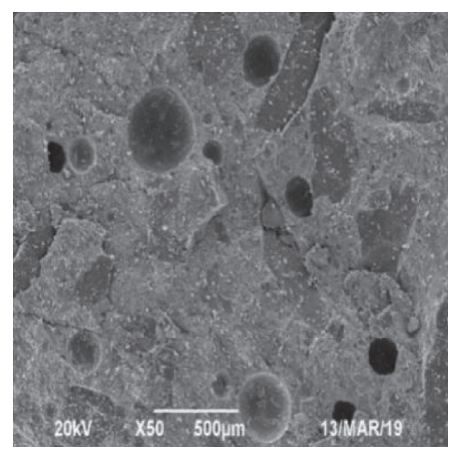

(d)

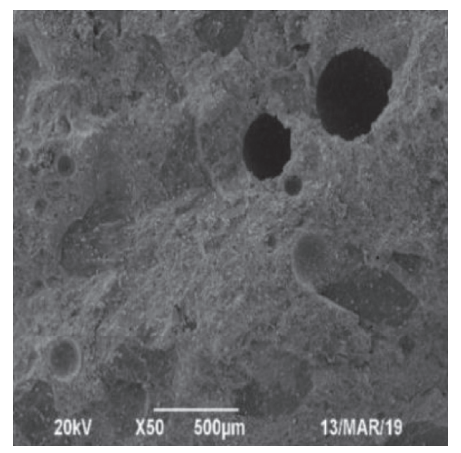

(g)

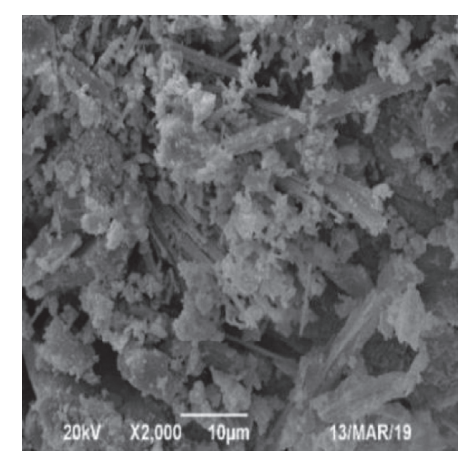

(b)

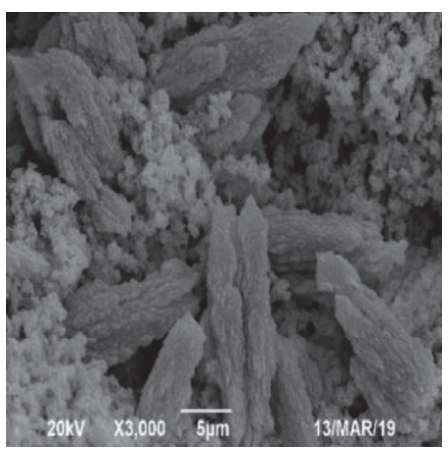

(e)

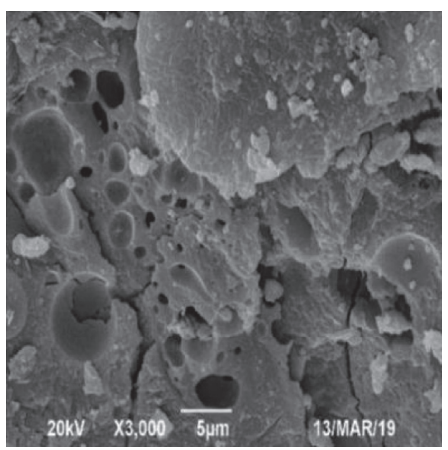

(h)

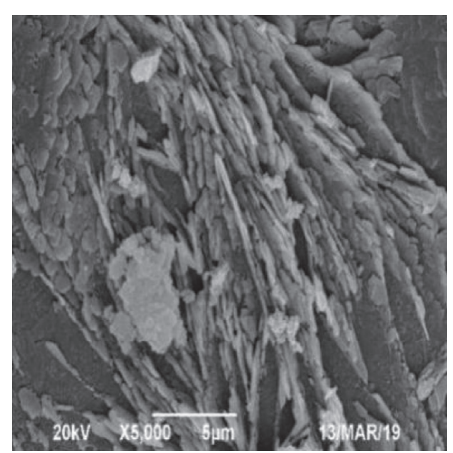

(c)

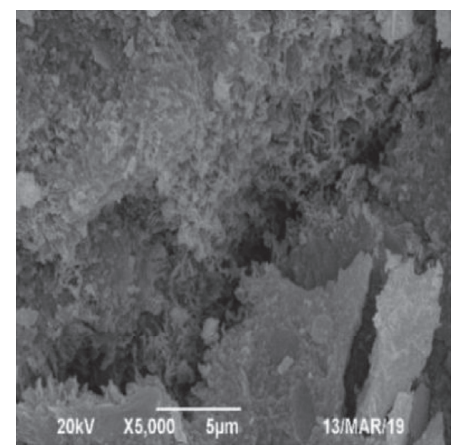

(f)

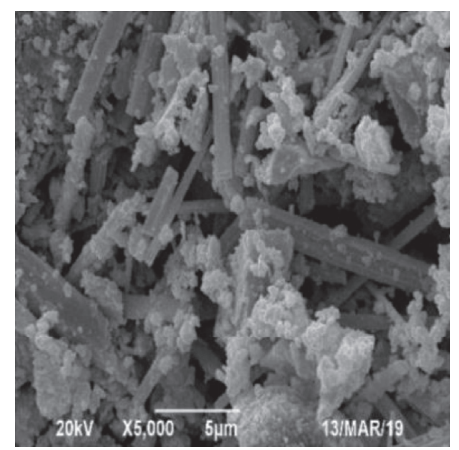

(i)

FIGURE 9: SEM images of the UHPC hydration products with different SRA dosages at $28 \mathrm{~d}$. (a) S0.5( $\times 50)$ image. (b) S0.5( $\times 2000)$ image. (c) S0.5(×5000) image. (d) S1(×50) image. (e) S1 (×2000) image. (f) S1 $\times 5000)$ image. (g) S2 $\times 550)$ image. (h) S2 (×2000) image. (i) S2 (×5000) image.

images in Figures 9(b) and 9(e), respectively. Figures 9(c), 9(f), and 9(i), on the other hand, show that the hydrated products such as ettringite and $\mathrm{Ca}(\mathrm{OH})_{2}$ did not form a tight alignment with an increase in the SRA content with the formation of the C-S-H gel being relatively low.

As previously mentioned in Section 4.2.1 of this paper, SRA has the function of entrained air and, thus, causes more harmful pores in concrete. At the same time, SRA can potentially delay the cement hydration process, making it impossible to produce enough hydration products to fill these pores in time. As the SRA dosage increases, this phenomenon becomes more pronounced. However, the shrinkage reduced by reducing the surface tension of the pore water because the SRA additive cannot fully compensate for the shrinkage caused by SRA's adverse effects on the internal structure of the UHPC paste. Therefore, the compressive and flexural strengths of UHPC will decrease with an increase in the SRA dosage, but vice versa for PEC.

\section{Conclusions and Recommendations}

The laboratory work presented in this paper successfully studied the fluidity, mechanical properties, and lowshrinkage characteristics of ultrahigh-performance concrete (UHPC) when modified with a shrinkage reducing agent (SRA) and Portland expanded cement (PEC) additives. In this study, the changes in the UHPC microstructure were characterized and analyzed using a scanning electron microscope (SEM). Based on the variation of the SRA and PEC dosages relative to the control UHPC without any additives as a function of aging (i.e., curing period), the following conclusions and recommendations were made: 
(1) With an increase in the SRA dosage, the UHPC fluidity at $0 \mathrm{~min}$ and $30 \mathrm{~min}$, respectively, exhibited an initially decreasing trend followed by a progressive increase. The fluidity was minimum at $1 \%$ SRA content. For SRA dosages exceeding 1\%, the fluidity gradually increased with an increase in the water-binder ratio.

(2) From the study results, it can be observed that SRA was helpful in restraining the autogenous shrinkage of UHPC. That is, with an increase in the SRA dosage, the ability to resist autogenous shrinkage also increased.

(3) In general, $0.5 \%$ SRA was found to be sufficient to effectively inhibit the drying shrinkage. However, as the SRA dosage increased, its inhibitory effects on drying shrinkage became inadequate to compensate for the shrinkage caused by its adverse effect on the UHPC matrix, ultimately increasing the drying shrinkage of the UHPC paste. Thus, as a single additive to UHPC, the recommended optimum SRA dosage should not exceed $0.5 \%$.

(4) PEC had an adverse effect on the fluidity of the UHPC paste, but vice versa on the early strength development of the UHPC.

(5) Whilst an increase in the PEC dosage increased the autogenous shrinkage of UHPC, it had some inhibition effects on drying shrinkage. With an appropriate PEC dosage, however, beneficial effects were registered on the UHPC fluidity and strength evolution. Thus, based on the study results and findings, $25 \% \sim 50 \%$ is recommended as the optimum PEC dosage.

Overall, this laboratory study has successfully quantified the effects of SRA and PEC additives on the fluidity, mechanical properties, shrinkage, and microstructure of UHPC under different aging conditions. Whilst the study results were plausible, correlation and validation of the proposed optimum dosage values (i.e., 0.5\% SRA, 1\% SRA, and 25\% 50\% PEC) with field performance data are strongly warranted in future studies. Nonetheless, the study beneficially contributes to enriching the literature through provision of a reference datum for the usage of SRA and PEC additives in UHPC.

\section{Data Availability}

The data used to support the findings of this study are available from the corresponding author upon request.

\section{Disclosure}

The contents of this paper, which is not a standard nor a design/bidding document, reflect the views of the authors who are solely responsible for the facts and accuracy of the data presented herein and do not necessarily reflect the official views or policies of any institution. Trade names were used solely for information purposes and not for product endorsement, advertisement, or certification.

\section{Conflicts of Interest}

The authors declare that they have no conflicts of interest regarding the publication of this study.

\section{Acknowledgments}

This work was supported by the Department of Transportation of Hunan Province Traffic Science and Technology and their help is greatly appreciated. Special thanks also go to all those who helped during this research study and write up of this paper.

\section{References}

[1] M. Singh, A. H. Sheikh, M. S. Mohamed Ali, P. Visintin, and M. C. Griffith, "Experimental and numerical study of the flexural behaviour of ultra-high performance fibre reinforced concrete beams," Construction and Building Materials, vol. 138, pp. 12-25, 2017.

[2] D.-Y. Yoo and N. Banthia, "Mechanical properties of ultrahigh-performance fiber-reinforced concrete: a review," Cement and Concrete Composites, vol. 73, pp. 267-280, 2016.

[3] D. Wang, C. Shi, Z. Wu, J. Xiao, Z. Huang, and Z. Fang, "A review on ultra high performance concrete: Part II. hydration, microstructure and properties," Construction and Building Materials, vol. 96, pp. 368-377, 2015.

[4] B. Chen, L Cong, and W. Huang, "Shrinkage review of ultrahigh performance concrete," Journal of Traffic and Transportation Engineering, vol. 18, no. 2, pp. 13-28, 2018, in Chinese.

[5] K. Liu, R. Yu, Z. Shui et al., "Optimization of autogenous shrinkage and microstructure for ultra-high performance concrete (UHPC) based on appropriate application of porous pumice," Construction and Building Materials, vol. 214, pp. 69-81, 2019.

[6] H. R. Sobuz, P. Visintin, M. S. Mohamed Ali, M. Singh, M. C. Griffith, and A. H. Sheikh, "Manufacturing ultra-high performance concrete utilising conventional materials and production methods," Construction and Building Materials, vol. 111, pp. 251-261, 2016.

[7] E. Holt and M. Leivo, "Cracking risks associated with early age shrinkage," Cement and Concrete Composites, vol. 26, no. 5, pp. 521-530, 2004.

[8] T. Xie, C. Fang, M. S. Mohamad Ali, and P. Visintin, "Characterizations of autogenous and drying shrinkage of ultra-high performance concrete (UHPC): an experimental study," Cement and Concrete Composites, vol. 91, pp. 156-173, 2018.

[9] M. Nasir, O. S. Baghabra Al-Amoudi, M. Maslehuddin, and M. Maslehuddin, "Effect of placement temperature and curing method on plastic shrinkage of plain and pozzolanic cement concretes under hot weather," Construction and Building Materials, vol. 152, pp. 943-953, 2017.

[10] M. José Oliveira, A. B. Ribeiro, and F. G. Branco, "Combined effect of expansive and shrinkage reducing admixtures to control autogenous shrinkage in self-compacting concrete," Construction and Building Materials, vol. 52, pp. 267-275, 2014.

[11] F. Liu, S. L. Shen, D. W. Hou, A. Arulrajah, and S. Horpibulsuk, "Enhancing behavior of large volume underground concrete structure using expansive agents," Construction and Building Materials, vol. 114, no. 49-55, 2016. 
[12] V. Afroughsabet, G. Geng, A. Lin, L. Biolzi, C. P. Ostertag, and P. J. M. Monteiro, "The influence of expansive cement on the mechanical, physical, and microstructural properties of hybrid-fiber-reinforced concrete," Cement and Concrete Composites, vol. 96, pp. 21-32, 2019.

[13] J. Liu, N. Farzadnia, C. Shi, and X. Ma, "Shrinkage and strength development of UHSC incorporating a hybrid system of SAP and SRA," Cement and Concrete Composites, vol. 97, pp. 175-189, 2019.

[14] P. Lura, B. Pease, G. Mazzotta, F. Rajabipour, and J. Weiss, "Influence of shrinkage reducing admixtures on development of plastic shrinkage cracks," ACI Materials Journal, vol. 104, no. 2, pp. 186-187, 2007.

[15] B. Hatami, A. M. Ramezanianpour, and A. S. Daryan, "Investigation on the effect of shrinkage reducing admixtures on shrinkage and durability of high performance concrete," Journal of Testing and Evaluation, vol. 46, no. 1, pp. 141-150, 2017.

[16] G. Shuling, W. Zhe, W. Wenchang, and Q. Huafang, "Effect of shrinkage-reducing admixture and expansive agent on mechanical properties and drying hrinkage of engineered cementitious composite (ECC)," Construction and Building Materials, vol. 179, pp. 172-185, 2018.

[17] R. D. T. Filho and M. A. Sanjuán, "Effect of low modulus sisal and polypropylene fibre on the free and restrained shrinkage of mortars at early age," Cement and Concrete Research, vol. 29, no. 10, pp. 1597-1604, 1999.

[18] J.-J. Park, D.-Y. Yoo, S.-W. Kim, and Y.-S. Yoon, "Benefits of using expansive and shrinkage-reducing agents in UHPC for volume stability," Magazine of Concrete Research, vol. 66, no. 14, pp. 745-750, 2014.

[19] H. Zheng-yu and Hu Gong-qiu, "Study on the shrinkage performance of ultra high performance concrete during heat curing," Materials Review, vol. 30, no. 4, pp. 115-120, 2016, in Chinese.

[20] S. Márquez, S. Hanson, and P. J. Tikalsky, "Environmental advantages of ternary cement combinations," in Proceedings of the 2nd International Symposium on Ultra High Performance Concrete, pp. 135-141, Kassel University Press, Kassel, Germany, March 2008.

[21] Z. Pan, Y. Zhu, D. Zhang, N. Chen, Y. Yang, and X. Cai, "Effect of expansive agents on the workability, crack resistance and durability of shrinkage-compensating concrete with low contents of fibers," Construction and Building Materials, vol. 259, Article ID 119768, 2020.

[22] J. Han, D. Jia, and P. Yan, "Understanding the shrinkage compensating ability of type K expansive agent in concrete," Construction and Building Materials, vol. 116, pp. 36-44, 2016.

[23] H. Kabir and R. D. Hooton, "Evaluating soundness of concrete containing shrinkage compensating MgO admixtures," Construction and Building Materials, vol. 253, Article ID 119141, 2020.

[24] J. Péra and J. Ambroise, "New applications of calcium sulfoaluminate cement," Cement and Concrete Research, vol. 34, no. 4, pp. 671-676, 2004.

[25] M. Rahman, Y. Chen, W. Lindquist, and A. Ibrahim, "Mitigation of shrinkage cracking in bridge decks using type-K cement," in Proceedings of the Structures Congress, pp. 125132, Fort Worth, Texas, April 2018.

[26] C. Ramseyer, "Shrinkage compensating concrete - past, present, and future," Concrete International, vol. 307, 2016.

[27] S. L. Sarkar, "Strength enhancement in type K expansive cement using additives," Journal of Materials in Civil Engineering, vol. 2, no. 1, pp. 1-14, 1990.
[28] B. Moffat, "Shrinkage-compensating concrete: an investigative study," in Proceedings of the Structures Congress, pp. 1-11, New York, NY, USA, April 2005.

[29] Gb/T2419-2005, Test Method for Fluidity of Cement Mortar, Standards Press of China, Beijing, China, 2005.

[30] Gb/T17671-1999, Method of Testing Cements-Determination of Strength (IOS), Standards Press of China, Beijing, China, 1999.

[31] O. M. Jensen and P. F. Hansen, "Water-entrained cementbased materials," Cement and Concrete Research, vol. 32, no. 6, pp. 973-978, 2002.

[32] Jgj/T70-2009, Standard for Test Method of Performance on Building Mortar, China Architecture \& Building Press, Beijing, China, 2009.

[33] F. Rajabipour, G. Sant, and J. Weiss, "Interactions between shrinkage reducing admixtures (SRA) and cement paste's pore solution," Cement and Concrete Research, vol. 38, no. 5, pp. 606-615, 2008.

[34] Z. Zhang, L. Xu, and M. Tang, "Effect of shrinkage reducing admixture on hydration and pore structure of cement-based materials," Journal of the Chinese Ceramic Society, vol. 72009, in Chinese.

[35] Zhao, Expanding Cement Research and Application, Daqing Petroleum Institute, Heilongjiang, China, 2008, in Chinese.

[36] S. Cotte, "Influence of recycled concrete aggregates from different sources in hot mix asphalt design," Construction and Building Materials, vol. 259, Article ID 120427, 2020.

[37] W. J. Weiss, B. Borichevsky, and S. P. Slish, "The influence of a shrinkage reducing admixture on the early-age shrinkage behavior of high-performance concrete," in Proceedings of the International Symposium on Utilization of High-Strength/ High-Performance Concrete, pp. 1339-1350, Sandefjord, Norway, May 1998.

[38] J. J. Brooks, M. A. Megat Johari, and M. Mazloom, "Effect of admixtures on the setting times of high-strength concrete," Cement and Concrete Composites, vol. 22, no. 4, pp. 293-301, 2000.

[39] Q. Fang, Study on the Effect of Shrinkage-Reducing Agents on the Properties of Cement-Based Materials, Zhejiang university, Zhejiang, China, 2015, in Chinese.

[40] D. P. Bentz, M. R. Geiker, and K. K. Hansen, "Shrinkagereducing admixtures and early-age desiccation in cement pastes and mortars," Cement and Concrete Research, vol. 31, no. 7, pp. 1075-1085, 2001.

[41] P.-m. Zhan and Z.-h. He, "Application of shrinkage reducing admixture in concrete: a review," Construction and Building Materials, vol. 201, pp. 676-690, 2019.

[42] S. Monosi, R. Troli, O. Favoni, and F. Tittarelli, "Effect of SRA on the expansive behaviour of mortars based on sulphoaluminate agent," Cement and Concrete Composites, vol. 33, no. 4, pp. 485-489, 2018.

[43] Y. Zhao, J. Gong, and S. Zhao, "Experimental study on shrinkage of HPC containing fly ash and ground granulated blast-furnace slag," Construction and Building Materials, vol. 155, pp. 145-153, 2017.

[44] J. Liu, C. Shi, N. Farzadnia, and X. Ma, "Effects of pretreated fine lightweight aggregate on shrinkage and pore structure of ultra-high strength concrete," Construction and Building Materials, vol. 204, pp. 276-287, 2019.

[45] M. Valipour and K. H. Khayat, "Coupled effect of shrinkagemitigating admixtures and saturated lightweight sand on shrinkage of UHPC for overlay applications," Construction and Building Materials, vol. 184, pp. 320-329, 2018. 
[46] P. C. Aitcin, A. Neville, and P. Acker, "Integrated view of shrinkage deformation," Concrete International, vol. 19, no. 9, pp. 35-41, 1997.

[47] V. Lilkov, N. Djabarov, G. Bechev, and K. Kolev, "Properties and hydration products of lightweight and expansive cements Part I," Cement and Concrete Research, vol. 29, no. 10, pp. 1635-1640, 1999.

[48] V. Lilkov, N. Djabarov, G. Bechev, and O. Petrov, "Properties and hydration products of lightweight and expansive cements Part II," Cement and Concrete Research, vol. 29, no. 10, pp. 1641-1646, 1999.

[49] E. Kassem, L. Walubita, T. Scullion, E. Masad, and A. Wimsatt, "Evaluation of full-depth asphalt pavement construction using X-ray computed tomography and ground penetrating radar," Journal of Performance of Constructed Facilities, vol. 22, no. 6, pp. 408-416, 2008.

[50] L. Walubita, B. Jamison, A. Alvarez, and X. Hu, "Air void characterisation of HMA gyratory laboratory-moulded samples and field cores using X-ray computed tomography (X-ray CT)," Journal of the South African Institution of Civil Engineers, vol. 54, no. 1, pp. 22-30, 2012. 